\title{
1 Survival strategies of Enterococcus mundtii in the gut of Spodoptera littoralis: a live report
}

3 Tilottama Mazumdar ${ }^{1}$, Beng Soon Teh $^{2}$, Aishwarya Murali ${ }^{4}$, Wolfgang Schmidt-Heck ${ }^{5}$, Yvonne

$4 \quad$ Schlenker $^{6},{\text { Heiko } \text { Vogel }^{3} \text { and Wilhelm Boland }}^{1}$

$5 \quad{ }^{1,2}$ Department of Bioorganic Chemistry, Max Planck Institute for Chemical Ecology, Jena,

6 Germany

$7 \quad{ }^{3}$ Department of Entomology, Max Planck Institute for Chemical Ecology, Jena, Germany

$8 \quad{ }^{4}$ Department of Microbiology, Friedrich Schiller University, Jena, Germany

$9 \quad{ }^{5}$ Systems Biology and Bioinformatics, Hans Knoll Institute, Jena, Germany

$10{ }^{6}$ Department of Internal Medicine, Friedrich Schiller University, Jena, Germany

12 Address correspondence to: Tilottama Mazumdar (tmazumdar@ice.mpg.de),

13 Wilhelm Boland (boland@ice.mpg.de)

14

15 Key words: Enterococcus mundtii, Spodoptera littoralis, Flow cytometry, Transcriptomics, 16 Foregut, Hindgut. 


\section{Abstract}

22 The complex interaction between a higher organism and its resident gut flora is a subject of

23 immense interest in the field of symbiosis. Many insects harbor a complex community of

24 microorganisms in their gut. Larvae of Spodoptera littoralis, a lepidopteran pest which is

25 prevalent in tropical and subtropical regions of the world, have a tube-like gut structure

26 containing a simple bacterial community. This community varies both spatially (along the

27 length of the gut) and temporally (during the life cycle of the insect).

28 To monitor the dynamics and rapid adaptation of microbes to the gut conditions, a GFP-tagged

29 reporter $E$. mundtii was constructed. After feeding to early instar S. littoralis larvae, the tagged-

30 microbes recovered from the fore and hind guts by flow cytometry. The fluorescent reporter

31 confirmed the persistence of E. mundtii in the gut. RNA-sequencing of the sorted bacteria

32 highlighted various strategies that the symbiont employs to survive, including upregulated

33 pathways for tolerating alkaline stress, forming biofilms and two-component signaling systems,

34 resisting oxidative stress and quorum sensing. Although these symbionts depend on the host for amino acid and fatty acids, differential regulation among various metabolic pathways points to an enriched lysine synthesis pathway in the hindgut of the larvae.

\section{Introduction}

39 Insects comprise the largest phylum of arthropods, according to the IUCN red list.

Microorganisms have been known to form symbiotic relationships with insects by supplying the

41 latter with essential nutrients, protection against pathogens, and aiding in digesting recalcitrant

42 organic matter. They contribute significantly to insects' ability to act as potential pathogens to 
43 animals, pests or pollinators of food crops, and as cyclers of carbon and nitrogen during the

44 decomposition of plant biomass (1)

45 There are several factors that determine the gut bacterial composition in insects. The gut can be

46 compartmentalized, resulting in structures that vary according to the complexity of the microbial

47 communities. Insects with a straight, tube-like gut usually possess a less diverse microbial

48 population compared to species with invaginations and deep pouches (1). Other factors that

49 shape the gut population include the following: oxygen level, gut $\mathrm{pH}$, the presence of digestive

50 enzymes, antimicrobial compounds, and insect diet $(2,3)$. Although most bacteria have an

51 affinity for neutral $\mathrm{pH}$, several acidophiles and alkalophiles have adapted to extreme $\mathrm{pH}$

52 conditions.

53 Gut microbes can be either vertically or horizontally transmitted. Vertical transmission allows

54 bacterial transfer (from the ovaries to the egg shells) to the next generation (4), whereas

55 horizontal transmission occurs over the course of the life cycle, through diet and social behavior.

56 Regardless of how bacteria are transmitted, microbial populations may be unstable during early

57 developmental stages $(5,6)$. For example, in holometabolous insects, a complete metamorphosis

58 of the gut occurs in the larva, through pupal and adult stages, resulting in microbial turnover and

59 variable microbial counts (5).

60 Insects are helped by their bacterial and fungal symbionts with functions relating to the digestion

61 of complex plant carbohydrates and amino acids, the assimilation of vitamins and the

62 development of defensive strategies against plants and animals (7), (8), (9). Higher animals

63 employ their resident gut symbionts for digestion of recalcitrant substrates. The plant cell-wall

64 component pectin is one example of a polymer, which in the leaf beetle Cassida rubiginosa

65 digests by employing an extracellular bacterium (10). Likewise, termites depend on their gut 
bacteria, archaea and eukaryotic gut symbionts for the breakdown and fermentation of plant fiber to acetate and methane. The gut microbiota further help in digesting xylan, arabinogalactan and carboxymethylcellulose, and can even work as a bio-reactor capable of mineralizing humus and nitrogen cycling $(11,12)$. Since the phloem sap is low in vitamins, amino acids and nitrogen, aphids have to rely on their primary symbiont, Buchnera aphidicola for nutrition. House crickets are hosts for Acheta domesticus bacteria in their hind guts, enabling the insects to utilize plant polysaccharides (2). In the course of evolution of plant-insect associations, insects have in several cases countered plant defensive strategies and managed to digest usually inaccessible, but highly nutritious plant polymers by acquiring several enzymes relating to digestion of complex plant carbohydrate through horizontal gene transfer (7). In other cases, functions relating to amino acid and vitamin assimilation (9), (13), and counter-defensive strategies against plants have been obtained by the insects from bacteria or fungi. For example, Burkholderia gladioli produce a mixture of antifungal antibiotics that protect the egg stages of Lagriinea beetles, which would otherwise be infected by the fungus P. lilacinum (14).

81 The cotton leafworm, Spodopera littoralis is a notorious pest feeding on a broad range of plants.

82 Larvae of this species have a longitudinal gut structure without compartments, increasing the 83 chances of flushing out bacteria, possibly preventing long-term colonization. This simple gut 84 structure could be one reason for the overall low gut-bacterial density observed in Lepidoptera 85 (1), (15). Despite the seemingly simple structure, a pH gradient exists along the gut: the anterior part and the midgut of lepidopteran larvae is highly alkaline, with a $\mathrm{pH}$ range of 11-12 (16), but

87 is neutral in the posterior part (17), which restricts the survival of many microbial species.

88 Despite the alkaline $\mathrm{pH}$, bacteria of the phylum Fermicutes, notably Enterococci and Clostridium 
sp. have emerged as core gut bacteria in the larval stages of Spodoptera littoralis (5). In

90 particular, the dominant E. mundtii has been shown to colonize the gut of S. littoralis throughout

91 different developmental stages (3), (5), (18).

92 Enterococci are successful colonizers of the gastrointestinal tract of humans, animals, and

93 insects. They can exert probiotic, positive effects which have been shown in humans (19).

94 Enterococcus mundtii is a gram positive, non-motile lactic acid bacterium abundantly found in

95 soil, human navel, cow teats and on hands of milkers. They are well adapted to dairy and plant

96 environment (20)

97 Antimicrobial activity has been shown for several Enterococci species, particularly E. mundtii isolated from a lepidopteran insect. E. mundtii produce an antimicrobial peptide called mundticin

$99 \mathrm{KS}$, that keeps potential pathobionts like Enterococcus fecalis and Enterococcus casseliflavus at the gut microbiome, the specific contributions of Enterococci in insects remain largely unknown. 
113 Results

114 The GFP-tagged reporter Enterococcus mundtii (18) was allowed to colonize the gut

115 environment of Spodoptera littoralis and was later recovered and sorted using flow cytometry to 116 compare its gene expression to that of $E$. mundtii grown in vitro.

The reporter bacteria of Enterococcus mundtii which were exposed to the gut conditions of Spodoptera littoralis larvae were sorted and isolated using flow cytometry. Next, the pooled bacteria were used to study changes in their transcriptome, as compared to the same bacteria

122 grown in Todd Hewitt Broth (THB). We chose THB-cultured E. mundtii grown in a shaker

123 incubator at 37 degree Celsius and 220 RPM as a control because these are ideal, stress-free

124 conditions. THB is a complete medium, in which bacteria can grow on dextrose as the source of

125 energy. Since the $\mathrm{pH}$ in $\mathrm{S}$. littoralis gut is alkaline in the foregut and neutral in the hindgut, we

126 focused on the E. mundtii growing at the two terminals of the gut.

127 From the gut homogenates containing the fluorescent reporter E. mundtii, 250,000 fluorescent

128 cells were sorted by a flow cytometer. The collected cells constituted 2 to $4 \%$ of the total

129 homogenate. In comparison, 250,000 fluorescent E. mundtii cells grown in vitro were also sorted

130 for our differential gene expression analysis (Fig. S1). 
133 The RNA extracted from the FACS-sorted E. mundtii cells was sequenced using the Illumina

134 Ultra-Low Input RNA kit and the resulting 10 million short reads per treatment and replicates

135 were processed and aligned against the fully sequenced genome of Enterococcus mundtii QU25

136 (23). Overall, the three replicates of bacterial cells isolated from foregut, hindgut and control had

137 varying levels of alignment percentages ranging from 17.5 to 55.5 , as shown in supplementary

138 table S2. Since the concentration of the RNA obtained from the FACS-sorted gut reporter $E$.

139 mundtii was low, we performed total RNA amplification. To maintain uniformity, the control

140 samples were treated the same way.

141 The numbers of up and down regulated genes between $E$. mundtii cells exposed to different $S$.

142 littoralis gut sections is shown Fig. 1. 284 and 275 genes are significantly differentially regulated

143 (fold change $=2, \mathrm{p} \leq 0.05$ ) in Enterococcus mundtii in the fore and hind guts, respectively.

144 Density plot in Fig. S3 shows the distribution of differentially expressed genes in foregut,

145 hindgut and control.

146 There are 169 genes in common between the E. mundtii exposed to the fore and hindguts that are

147 differentially regulated when compared to the control. Most of these common genes belong to

148 mechanisms required by E. mundtii to colonize by adhering to the gut wall, avoid stresses, and

149 acquire iron and complex carbohydrates ((Fig.1), (supplementary S7)).

150 To test for biological and technical variability, individual replicates were analyzed and a PCA

151 plot (Fig. 2) and dendrogram (Fig. 3) were generated. The gene expression profiles of E. mundtii

152 from the insect gut and the control form separate clusters and nodes, clearly separating them

153 from each other. 


\begin{tabular}{|l|l|l|l|}
\hline & $\begin{array}{l}\text { E. mundtii in } \\
\text { fore gut vs control } \\
(\mathrm{p}<\mathbf{0 . 0 5})\end{array}$ & $\begin{array}{l}\text { E. mundtii in } \\
\text { hind gut vscontrol } \\
(\mathrm{p}<0.05)\end{array}$ & $\begin{array}{l}\text { E. mundtii in } \\
\text { forevshind gut } \\
(\mathrm{p}<0.05)\end{array}$ \\
\hline $\begin{array}{l}\text { No. of genes } \\
\text { Upregulated }\end{array}$ & 91 & 71 & 28 \\
\hline $\begin{array}{l}\text { No. of genes } \\
\text { downregulated }\end{array}$ & 193 & 204 & 60 \\
\hline
\end{tabular}

156 Table 1: Table showing the numbers of significantly differentially expressed genes - up- and

157 downregulated $(\mathrm{p} \leq 0.05)$ in Enterococcus mundtii - by comparing the following conditions: $E$. 158 mundtii living in foregut vs control, hindgut vs control and foregut vs hindgut.

Genes significantly differentially regulated in:

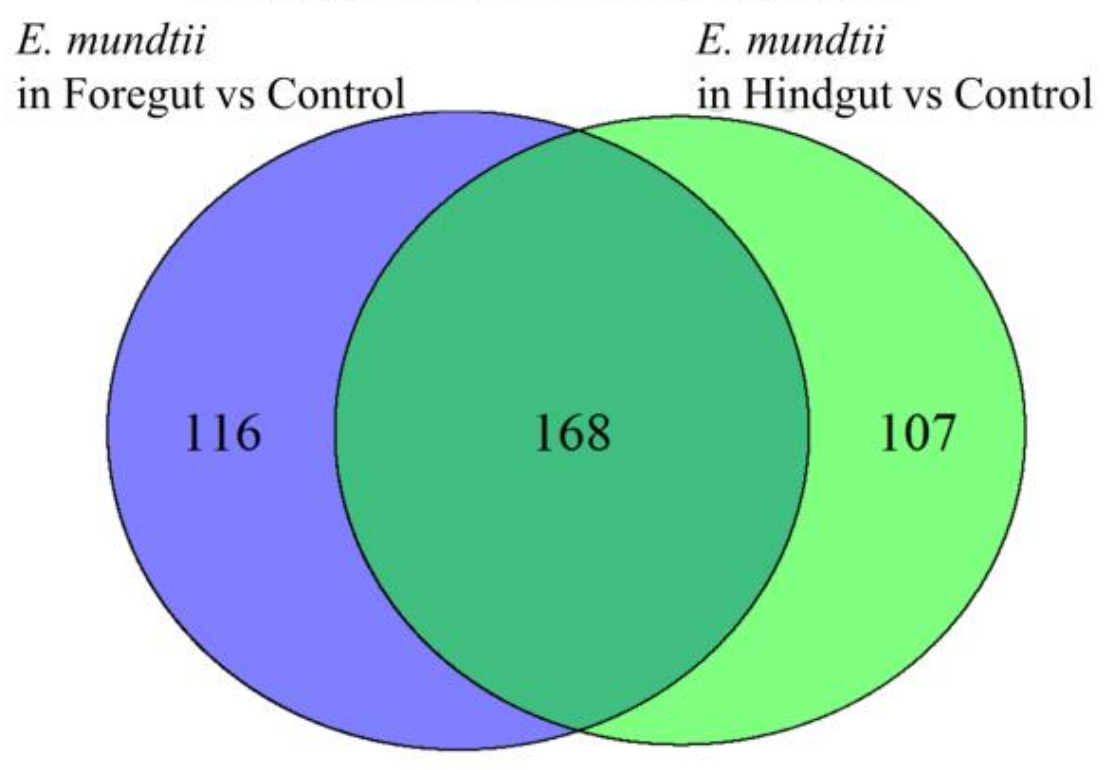

Figure 1: Venn diagram showing overlap of significantly differentially expressed genes

161 (supplementary) in the following two conditions: E. mundtii living in foregut vs control, and $E$. mundtii living in hindgut vs control. 


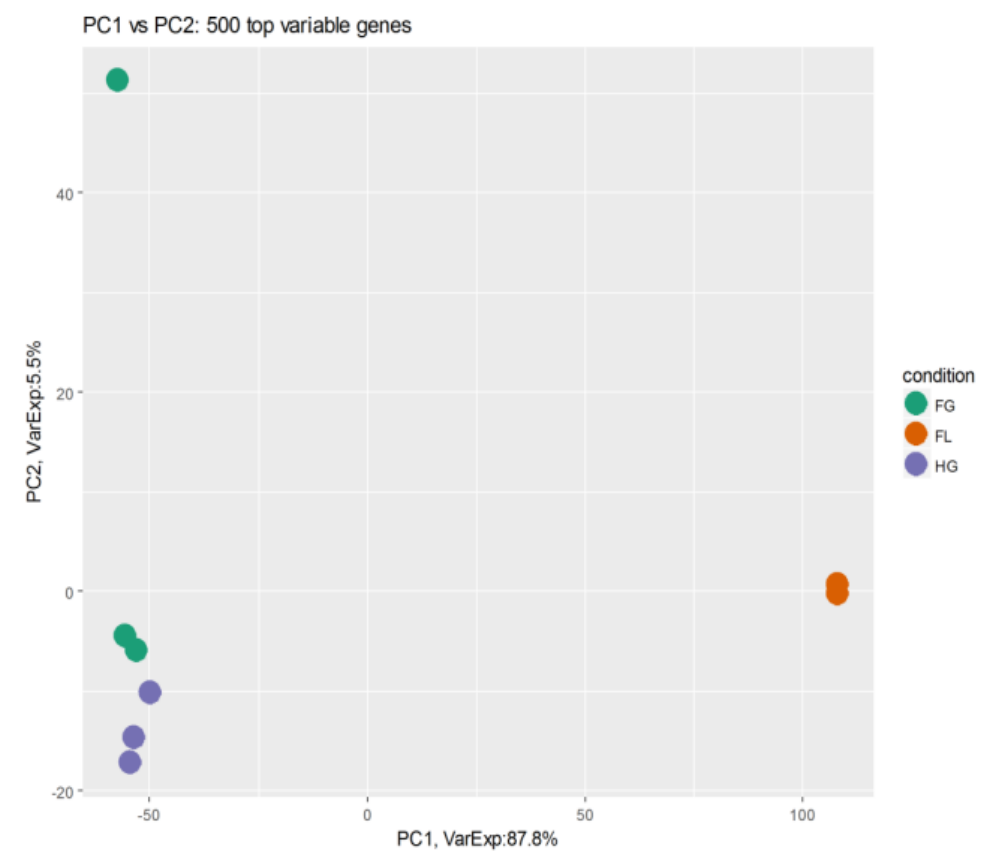

166 Figure 2: PCA plot showing clustering of the transcriptomic profiles among the three technical 167 replicates of $E$. mundtii obtained from the foregut (FG), hindgut (HG) and control (FL).

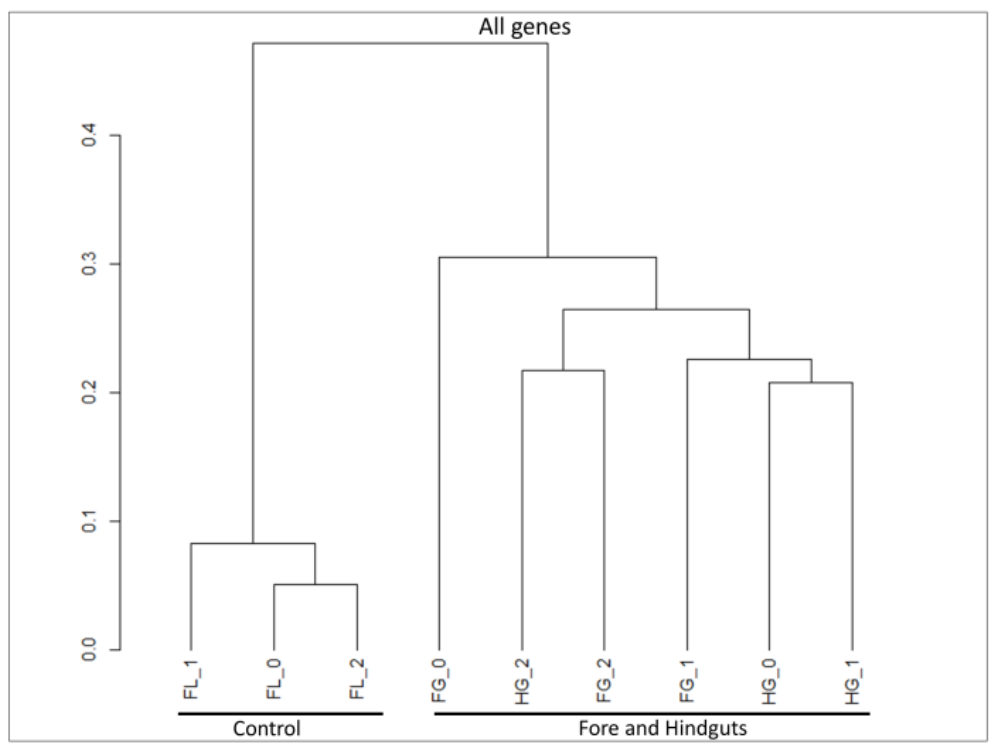


Figure 3: Dendrogram showing hierarchical clustering among the three replicates of transcriptomes analyzed from E. mundtii obtained from the foregut, hindgut and control. The gene expression profiles from the foreguts (FGs) and the hindguts (HGs) partially overlap and cluster away from the control (FL) profile.

\section{Annotations based on gene ontology of proteins}

The full picture of the pathways from E. mundtii living in the gut of S. littoralis is evident in Fig.

4. The differentially expressed genes have been classified according to the three categories of gene ontology: molecular function, biological process and cellular components. We only discuss the category of biological processes, which highlights the major pathways the bacteria are involved in when they are living in the gut of the host.

Peptidoglycan turnover is a sign of active cell division. Peptidoglycan biosynthetic and catabolic processes show upregulation in both fore- and hindguts. The N-acetylmuramoyl-Lalanine amidase enzyme in the foregut helps in cell separation during division (24). It also aids in cell motility and establishing a symbiotic association with the host (4).

Next task for E. mundtii would be to adhere to the host gut epithelium. Accordingly, the category Cell adhesion is enriched, which could indicate that the bacteria are involved in attaching and adhering to the host epithelium to prevent the flushing out of the host gut.

Aerobic respiration in insects and the electron transport chain in the mitochondria lead to reduction of oxygen to water and formation of ATP, resulting in the production of reactive oxygen species (ROS) at the gut membrane (25). Symbionts need to be able to respond to oxidative stress in order to live in the gut.

Certain metabolic pathways are worth mentioning: 
193 Nucleotide metabolism seems to be a key aspect for bacterial colonization and adaptation to the

194 host gut (26). Several enzymes required for purine and pyrimidine metabolism are upregulated.

195 An upregulation in starch and sucrose metabolism indicates that the symbionts are able to

196 metabolize these complex sugars most readily because these are components of the larvae's

197 plant-based carbohydrate diet. The larvae show enriched alpha amylase activity, along with

198 starch and sucrose metabolic processes in the foregut (27).

199 Not only the synthesis of amino acids such as phenylalanine, glutamate, tyrosine and

200 tryptophan, but also fatty acid biosynthesis (shown by the downregulation of acetyl CoA

201 carboxylase activity, malonyl CoA biosynthetic activity) and metabolism in general seem to be

202 downregulated in the symbiont. There is a concomitant upregulation of fatty acid degradation

203 when E. mundtii lives in the gut (Fig. S4). Perhaps by obtaining these by-products from the host,

204 symbionts avoid the energy costs associated with these processes.

205 However, in the E. mundtii that reside in the hindgut, lysine biosynthesis via the

206 diaminopimelate pathway is upregulated. Most likely this essential amino acid is provided to the

207 host and may get reabsorbed in gut of S. littoralis (9) (Fig. 4(a, b)). 
bioRxiv preprint doi: https://doi.org/10.1101/2020.02.03.932053; this version posted February 4, 2020. The copyright holder for this preprint (which was not certified by peer review) is the author/funder. All rights reserved. No reuse allowed without permission.

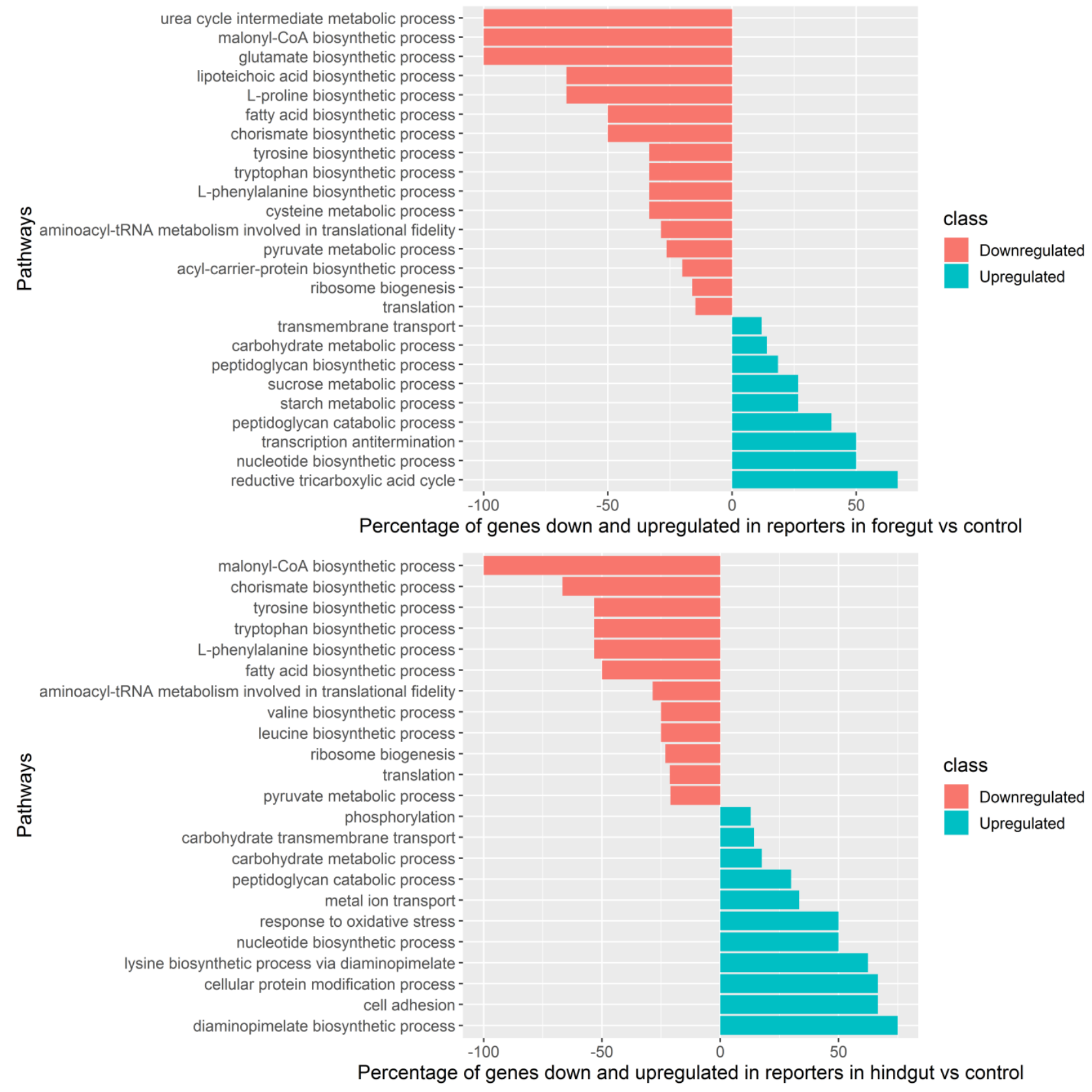

Percentage of genes down and upregulated in reporters in hindgut vs control

211 Figure 4: Summary of gene ontology classification in the category of biological processes. The

212 graph shows both up- and downregulation of the assembled genes of E. mundtii obtained from

213 foregut (a) and hindgut (b), as compared to genes of the control. 


\section{Survival strategies of $E$. mundtii in the gut of $S$. littoralis}

217 The differentially expressed genes that were identified pertained to the adaptive strategies of $E$.

218 mundtii in the fore- and hindguts of the larvae. We classified their strategies in three broad

219 categories: extracellular interactions, stress responses and metabolism.

\section{a) Extracellular interaction}

221 Bacterial adherence to the gut tissue is the first step towards a successful colonization of bacteria

222 in the host gut to prevent bacteria from being flushed out of the system and to survive the

223 epithelial turnover (28).

224 Various well-characterized surface-associated proteins with conserved motifs and domains

225 contribute to the attachment of $E$. mundtii to the gut epithelial tissue of the host. C-terminal

226 conserved LPxTG motif (EMQU_1297: 26 and 40 folds in fore- and hindgut, a slight

227 upregulation of fms3) and WXL domains (EMQU_0541: 30 and 8 folds in fore- and hindgut and

228 EMQU_0539: 383 folds in foregut) are two such well-characterized and conserved parts of

229 proteins that help bacteria to attach successfully to the host gut. Adhesion, the first step towards

230 biofilm formation, is mediated by competition for nutrients. The lys $M$ domain helping in biofilm

231 formation (29) by surface attachment is upregulated (EMQU_0157: up to 3 folds in fore- and

232 hindguts). The sticky matrix helps Enterococcus mundtii to deal with stress efficiently (28). The

233 agr two-component systems may bring about quorum sensing in bacteria; when they come close

234 together, the labor required to adapt to a new environment is divided among individuals. Levels

235 of agrA are upregulated about 3-folds in the hind gut and for $\operatorname{agrB}$ about 5 and 8 folds in fore-

236 and hindguts, respectively (30). 
237 Chitin-binding proteins form a class of surface-associated proteins that provide adhesive

238 properties to lactic acid bacteria so that these can adhere to the $\mathrm{N}$-acetyl glucosamine component

239 of chitin present in insects' gut epithelial cells, especially the cells lining the midgut (31). Two of

240 these proteins show levels as high as EMQU_0940: 47 and 138 folds and EMQU_1285: 25 and

24169 folds, in fore- and hindguts, respectively (32).

242 Lipoproteins are placed at defined subcellular spaces formed by the plasma membrane. Their

243 position is convenient to capture incoming nutrients or elements such as iron. Also, they have

244 been shown to play roles in adhesion to host cells as well (33) (34). EMQU_0428 is upregulated

245 by 5 and 4 folds in fore and hind gut respectively. EMQU_2743 is 7 folds upregulated in hind

246 gut. Both are zinc transporter lipoproteins (Fig. 5, supplementary S5). 
secE: general secretory pathway preprotein (Quorum sensing) murG: UDP-N-acetylglucosamine/LPS N-acetylglucosaminetransferase (Peptidoglycan biosynthesis)

murD: UDP-N-acetylmuramoylalanine--D-glutamate ligase ( D-Glutamine and D-glutamate metabolism)

Zinc transport system adhesion lipoprotein

Cell surface protein containing LPXTG-motif

Chitin binding protein

Putative lipoprotein

ftsW3: Cell division protein

Chitin binding protein

wxl domain surface protein

wxl domain surface protein

lysM family surface protein

Zinc-binding lipoprotein AdaC

murF: UDP-N-acetylmuramoyl-tripeptide--D-alanyl-D-alanine ligase (Peptidoglycan biosynthesis)

Figure 5: Heatmap showing the regulation of certain genes helping in the attachment of $E$. mundtii, when these bacteria are in the fore and hind guts of Spodoptera littoralis

\section{b) Stress responses}

254 Bacteria modulate their gene expression to abate the various stresses they encounter in the environment.

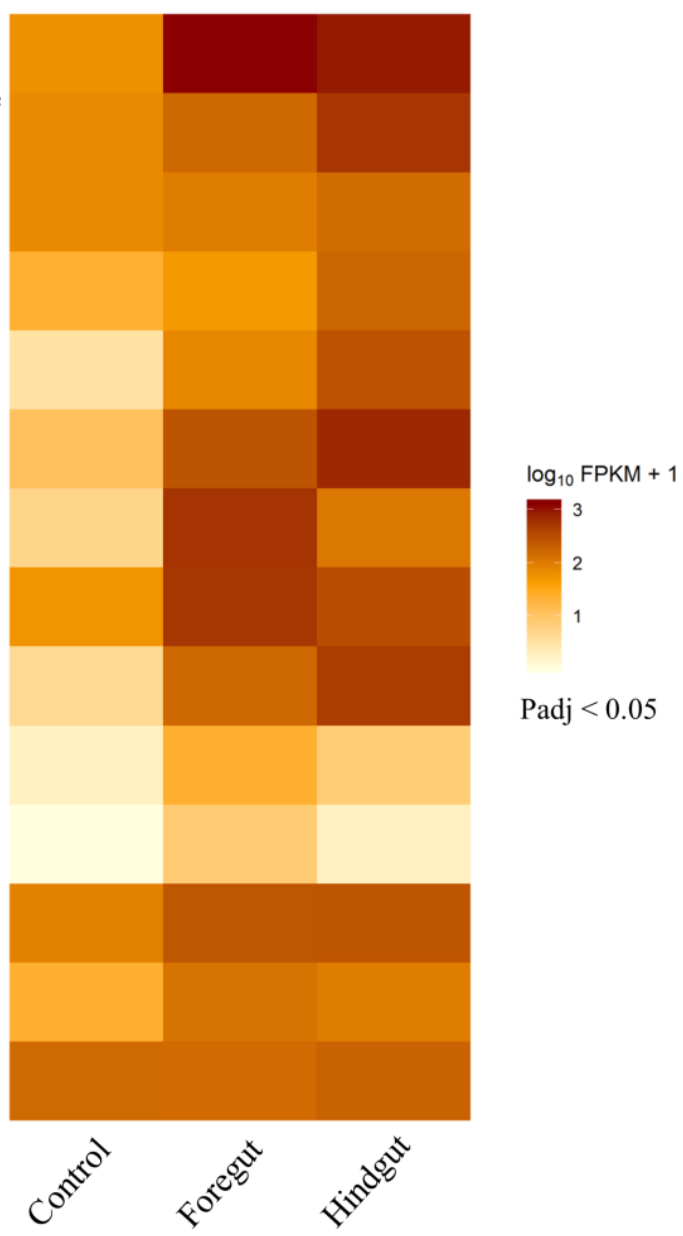

$\log _{10}$ FPKM +1

$\operatorname{Padj}<0.05$ 
257 E. mundtii residing in the insect gut are exposed to oxidative stress resulting from the host

258 metabolism. Accordingly, they upregulate several antioxidant enzymes: superoxide dismutase

259 (13 and 8 folds in fore- and hindguts, respectively), catalase (EMQU_0568 : 4 and 10 folds in

260 fore- and hindguts, respectively), NADH oxidase- peroxidase cycle (EMQU_0335, 0459, 1279;

261 up to 4-folds in the hindgut), organic hydro peroxide resistance family protein (EMQU_1453: 6

262 folds in fore- and hindguts), and peptide-methionine (R)-S-oxide reductase (EMQU_0165: 3-

263 folds in hindguts).

264 General stress proteins ( $g l s B: 25$ and 43 folds; $g l s B 1: 11$ and 8 folds; $g l s 33: 7$ and 19 folds, in

265 fore- and hindguts, respectively) and universal stress proteins (USPs) (uspA2: 33 and 12 folds in

266 fore- and hindguts, respectively) are upregulated in E. mundtii in response to environmental

267 conditions such as salt, oxygen or oxidative stresses, toxic substances and nutrient starvation.

268 The expression of USPs may depend on increased bacterial density, brought about by quorum

269 sensing (36).

270 Intracellular trafficking, secretion, and vesicular transport include secE (19 and 16 folds in fore-

271 and hindguts, respectively) needed for cell viability (37), and virD4 components (31 and 30 folds

272 in fore- and hindguts, respectively) of the type IV secretion system, which are all upregulated.

273 Repair proteins such as MutS (EMQU_2803) conferring DNA mismatch repair and its protection

274 from oxidative stress are slightly upregulated). So is the recA (EMQU_2752: 2 folds in the

275 foregut) operon that was shown to be upregulated during oxidative stress (38); recF for

276 recombination repair (39), whose general role is maintenance of DNA is upregulated (2 and 3

277 folds in fore- and hindguts, respectively) (40). 
DNA alkylation repair protein (AlkD) is upregulated 2 and 3 folds in fore- and hindguts,

279 respectively (41). Also, RadA (3 and 7 folds in fore- and hindguts) and RadC ( 2 folds in foreand hindguts) proteins helping in DNA repair and recombination show the same trend (42). and hindguts, respectively) constitute a toxin-antitoxin system that plays a role in biofilm formation (43) (Fig. 6, supplementary S5).

$$
\begin{array}{r}
\text { uspA2: Universal stress protein } \\
\text { mecA: Adapter protein } \\
\text { glsB1: General stress protein } \\
\text { glsB: General stress protein } \\
\text { gls33: General stress protein } \\
\text { DNA damage-inducible-protein } \mathrm{J}
\end{array}
$$

Pheromone cAD1 precursor lipoprotein (Quorum sensing) RadA: DNA repair protein

AgrC: Two-component system, sensor histidine kinase (Quorum sensing)

AgrA: Two-component system, response regulator (Quorum sensing) Organic hydroperoxide resistance family protein (oxidative stress) VirD4:type IV secretion system protein (Environmental Information Processing)

Fur family ferric uptake regulator RecX: recombination regulatory protein Magnesium containing catalase (oxidative stress) NADH peroxidase (oxidative stress) AgrB: accessory gene regulator B (Quorum sensing) NADH oxidase (oxidative stress) FetC: Iron complex transport system ATP-binding protein

Asp: Alkaline shock protein AlkD: DNA alkylation repair protein
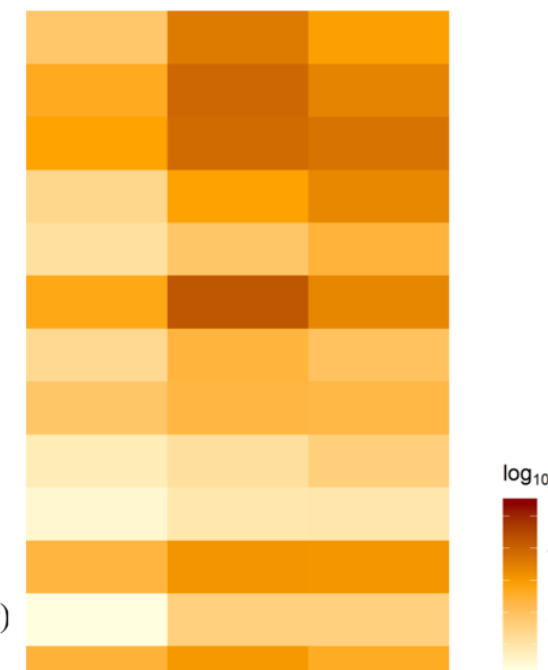

Padj $<0.05$ 
286

287

288

289

290

291

292

293

294

295

296

297

298

299

300

301

302

303

304

305

306

307

Figure 6: Heatmap showing the regulation of certain genes that help in the stress tolerance of $E$. mundtii, when these bacteria are in the fore and hind guts of Spodoptera littoralis

\section{Iron homeostasis}

Iron homeostasis in E. mundtii is important especially in environments that are iron depleted, owing to the compound 8-HQA. These bacteria have upregulated their fetC permease gene to increase their ferric uptake ( 7 folds in the foregut and 11 folds in the hindgut) and FUR family transcriptional regulator (EMQU_1067: 4 folds in the foregut) (FetC permease assists in siderophore-mediated iron uptake) (44). Adaptation that is mediated through FUR and iron uptake is common in iron-deprived environments (45) (Fig.6, supplementary S5).

\section{Dealing with alkaline stress}

The highly alkaline $\mathrm{pH}$ characteristic especially of the foregut of larvae is a challenge to bacteria in general but also to E. mundtii specifically. For example, alkaline $\mathrm{pH}$ has been proven to unwind the double helical structure of DNA (46). In addition, the alkaline stress protein, which has been reported to accumulate in the cell membrane of Staphylococcus aureus in alkaline conditions (47), shows high expression levels in E. mundtii living in the alkaline foregut (7 folds), while its expression decreases in the neutral conditions of the hindgut. In Enterococcus faecalis, several genes are differentially expressed in alkaline conditions; similar expression patterns characterize Enterococcus mundtii, if alkalinity is the only factor taken into consideration. For example, we found a downregulation of methionine transport and synthesis systems, $\mathrm{Na}^{+} \mathrm{H}^{+}$antiporter (NhaC family, 1 fold downregulation), upregulation of adenosine and 


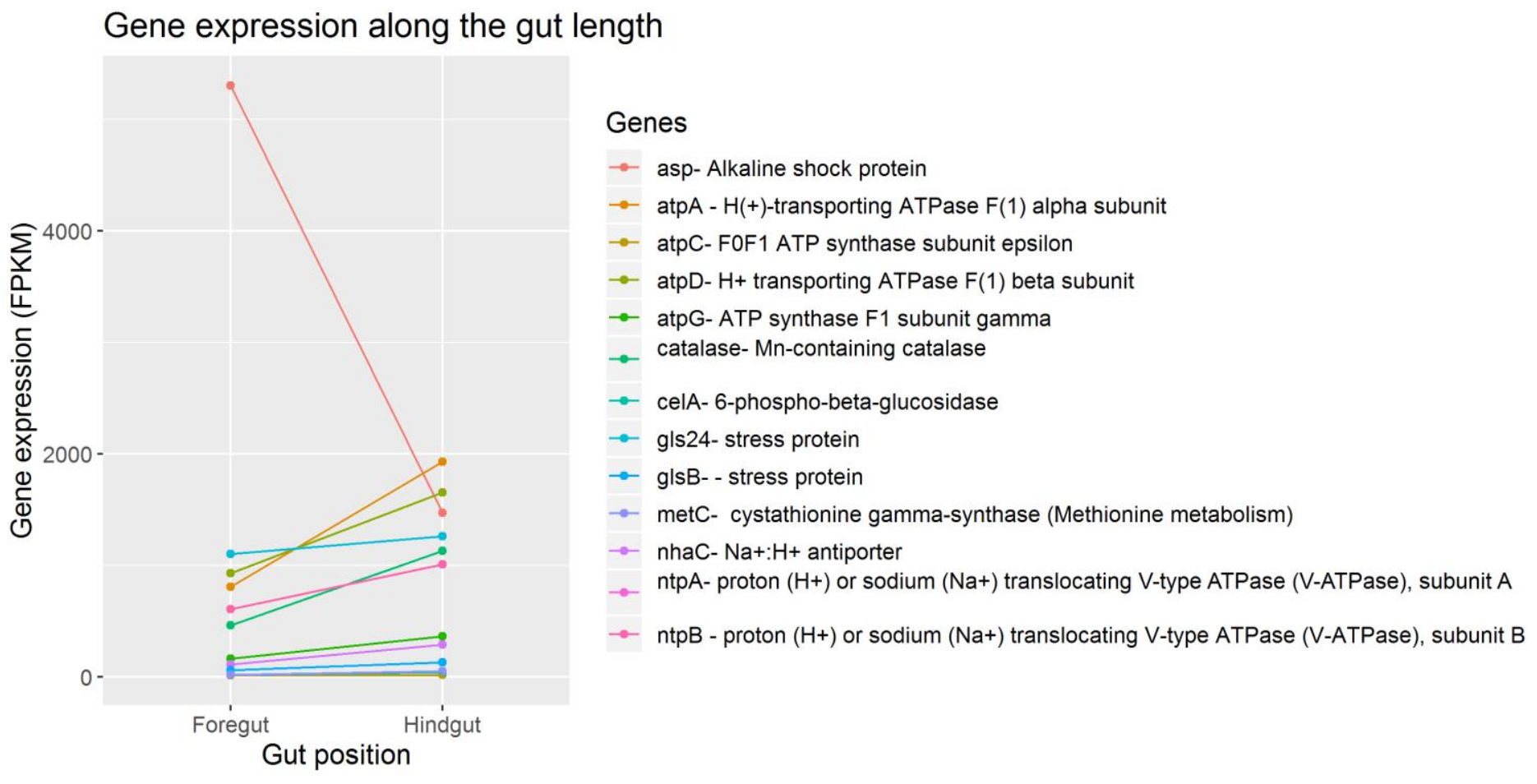

313 Figure 7: Graph showing the regulation of certain $\mathrm{pH}-$ related genes in E. mundtii living in the

314 fore and hind guts of S. littoralis larval gut.

\section{c) Metabolism}

317 Facultative anaerobes can switch between respiration and fermentation, based on oxygen

318 availability. Most glycolytic genes - for example, glucokinase ( $g l c K)$, 1-phosphofructo kinase

319 (fruK), 6-phospho-beta-glucosidase $(b g l P, b g l B, b g l G)$ phosphofructokinase A ( $p f k A)$ and 
320 glucose-6-phosphate isomerase- in the E. mundtii dwelling in the gut do not show much change

321 in expression compared to those growing under control conditions, suggesting that glycolysis

322 has not been stopped completely. The same trend holds true for pyruvate dehydrogenase for

323 entering the citric acid cycle in aerobic condition, along with lactate dehydrogenase (ldhA

324 EMQU_2453). The protein that stimulates the sugar fermentation (SfsA-EMQU_0871) under

325 anaerobic conditions is upregulated 10 and 7 folds in fore- and hindguts, respectively. Some

326 alcohol dehydrogenases are upregulated to convert acetaldehyde to ethanol in the fermentative

327 pathway (EMQU_1129, 1 fold in hindgut; EMQU_ 0525, 5 folds in fore- and hindguts, and

328 EMQU_0315, 3 and 4 folds in fore- and hindguts). The acetyl CoA produced by pyruvate

329 dehydrogenase does not significantly contribute to the production of fatty acids and amino acids,

330 because both pathways are downregulated (Fig. S4).

331 Phosphotransferase systems (PTSs) for taking up alternative source of sugars such as sucrose,

332 ascorbate, mannose and, most importantly, cellobiose, are upregulated in E. mundtii in both

333 fore- and hindguts. Cellobiose comes from the plant products on which the host is fed. There are

334 at least 8 PTS cellobiose transporters upregulated with fold-changes as high as 39 and 42 in the

335 fore- and hindguts, respectively. Ascorbate is mostly taken up in the hindgut. On the other hand,

336 fructose and lactose do not seem to be a popular source of energy.

337 There is a dramatic increase in starch and sucrose metabolism brought about by an increase in

338 the sucrose-specific PTS transporter (EMQU_2136: 1 and 5 folds in fore- and hindguts,

339 respectively) and sucrose 6-phosphate dehydrogenase (scrB: 2 folds in the hindgut); and the

340 alpha-amylase enzyme neopullanase (EMQU_1435: 52 and 30 folds in the fore- and hindguts,

341 respectively). 
bioRxiv preprint doi: https://doi.org/10.1101/2020.02.03.932053; this version posted February 4, 2020. The copyright holder for this preprint (which was not certified by peer review) is the author/funder. All rights reserved. No reuse allowed without permission.

342 There is an increased metabolism and transport of nucleotides in E. mundtii living in the gut (26).

344 Regarding glycerol metabolism, the $g l p F$ gene required for glycerol uptake is downregulated (4

345 folds in the foregut), whereas the ones for metabolism- $g \operatorname{lp} O$, $d h a K L, g l p Q$ are still expressed,

Zwf: Glucose-6-phosphate 1-dehydrogenase (Pentose phosphate pathway) sfsA: Sugar fermentation stimulation protein A

pyk: Pyruvate kinase ptsG: PTS family glucose transporter pfkA: 6-phosphofructokinase glcK: Glucokinase gap: Glyceraldehyde 3-phosphate dehydrogenase PTS system, fructose-specific IIC component, fructose uptake PTS system, mannose-specific IID component, mannose uptake

tetR/AcrR family transcriptional regulator 2-dehydro-3-deoxygluconokinase (carbohydrate kinase) 6-phospho-beta-glucosidase (Glycolysis / Gluconeogenesis) PTS system, sucrose-specific IIA component, sucrose uptake DeoR family, carbon catabolite repression regulator 1-phosphofructokinase (Carbohydrate metabolism) Malolactic regulator Acyl-carrier-protein S-malonyltransferase (Fatty Acid Biosynthesis) ptsH: PTS system transporter, phospho carrier protein PTS system, cellobiose-specific IIC component, Starch and sucrose metabolism PTS system transporter subunit IIA, Starch and sucrose metabolism PTS system transporter subunit IIB, Starch and sucrose metabolism glutamine synthetase (Arginine biosynthesis) 6-phospho-beta-glucosidase (Starch and sucrose metabolism )

MFS transporter, multidrug resistance protein Ribose-phosphate pyrophosphokinase ( Pentose phosphate pathway, purine metabolism) Trehalose-6-phosphate hydrolase (Starch and sucrose metabolism) PTS system, maltose-specific IIB component (maltose uptake)

Glucan 1,6-alpha-glucosidase APC family amino acid transporter (glutamate:GABA antiporter) PTS system, cellobiose-specific IIA component

fba: Fructose-bisphosphate aldolase dhaL: Glycerone kinase subunit csck3: Fructokinase (Fructose and mannose metabolism) bglH: phospho-beta-glucosidase (Glycolysis / Gluconeogenesis)

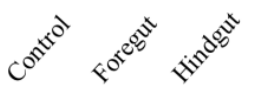

$\log _{10}$ FPKM +1

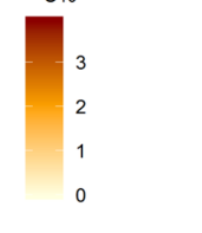

$\operatorname{Padj}<0.05$ 
Figure 8: Heatmap showing the regulation of some genes in E. mundtii are involved in metabolism when they are in the fore and hind guts of Spodoptera littoralis

\section{Discussion}

This work focuses on the survival strategies of Enterococcus mundtii in the gut of Spodoptera littoralis, an environment threatened by stressful conditions, namely high $\mathrm{pH}$, low iron content and oxidative stress. This makes it a good system to study adaptation by the symbionts in the larval gut. This motivated us to send down the larval guts, GFP- tagged reporter E. mundtii,

356 which is a dominant bacterium (18), in order to study how its mechanisms of adaptations to the 357 new environment. The fed fluorescent bacteria were later retrieved from the fore and hindguts of 358 the larvae using flow cytometry. Care was taken to halt any kind of metabolic changes that might 359 have occurred between the individual experimental steps of larval dissection and FACS sorting, using RNAlater and RNAprotect reagents. Comparing the gene expression profiles of these

361 retrieved reporters with those of E. mundtii grown under optimal culture conditions, we were

362 able to obtain a snapshot of the genes and the pathways that help these symbionts to survive and 363 adapt to the gut of $S$. littoralis larvae. The transcriptional changes found in these bacteria are an 364 amalgamated result of all these factors.

365 We managed to obtain a real-time scenario of how E. mundtii is abating stress and colonizing its 366 host gut (Fig. 9).

367 The ability to adhere to the host gut epithelium is an important prerequisite for the bacteria to 368 successfully colonize and establish a host-microbe association. Most of the adhesive properties 369 of lactobacilli are accounted for by their cell surface properties (49). 
Our transcriptomic analyses show that E. mundtii attaches well to the host surface, as was also

371

372

374

375

376

377

378

379

380

381

382

383

384 seen earlier by FISH imaging before (5). This is brought about by a set of adhering proteins.

LPxTG is a sortase-dependent site for anchoring proteins, covalently attached to the peptidoglycan (50), (51). Lipid-anchored proteins or lipoproteins constitute another class of covalently associated adhesion proteins (49), which shows upregulation in E. mundtii. Wxl domains and LysM, or lysine-dependent motif binding to the peptidoglycan, form non-covalent associations with the peptidoglycan (52), (53), (52). The occurrence of such associations was proven in Enterococcus fecalis (54). Chitin is a major part of the peritrophic matrix, which in turn lines the midgut epithelium of the host (55), (56). Chitin-binding proteins in E. mundtii also promote adherence to the host gut. Several bacteria such as L. monocytogenes, adherent E. coli and $V$. cholerae were found to initiate their adhesive process using their chitin-binding proteins in the host gut (57).

E. mundtii dwelling in the gut employ various strategies to survive adverse conditions, upregulating general and universal stress proteins to survive heat, $\mathrm{pH}$ and oxidative stress. Mechanisms to abate oxidative stress are a necessity for organisms living in an actively metabolizing environment. Reactive oxygen species result from reduction of oxygen. Thereafter, the dismutation product of the superoxide anion $\left(\mathrm{O}_{2}{ }^{-}\right)$is hydrogen peroxide $\left(\mathrm{H}_{2} \mathrm{O}_{2}\right)(58) . \mathrm{O}_{2}{ }^{-}$and $\mathrm{H}_{2} \mathrm{O}_{2}$, along with the hydroxyl radical, are potent oxidants that can abstract electrons from DNA, proteins, lipids, other macromolecules, causing damage to the invading or residing symbionts (59). Lactobacilli employ enzymes such as NADH oxidase/peroxidase, superoxide dismutase and manganese-dependent catalase to counteract ROS (60).

Several bacteria have been found to have general and universal stress proteins, aiding their adaptation to stresses such as temperature, oxidative, nutrient starvation and toxic agents (61). 
393 The first reported universal stress protein in E. coli was found in fungi, archaea, plants and even

394 flies (62). In Burkholderi aglumae, universal stress proteins genes regulated by quorum sensing

395 (61). Confronted with stress, E. mundtii seems capable of behaving like a multicellular organism.

396 The bacteria rely on quorum sensing as a survival strategy, aggregating on the host epithelia and

397 forming a biofilm in the host gut. That agrABCD forms a two-component system and brings

398 about quorum sensing has already been established in fellow fermicute Staphylococcus aureus

399 and Streptococcus pneumoniae (63). The bacterial adherence properties of E. mundtii may help

400 form a biofilm layer on the gut wall. Thus, these two inter-related phenomena, quorum sensing

401 and biofilm formation, and help bacteria to adapt to altered environments.

402 As discussed, 8-HQA produced by the larvae is an iron chelator, and the symbionts must employ

403

mechanisms to survive in an iron-depleted environment. The FetC iron complex transport

404 permease and FUR family of transcriptional regulators seem to have similar goals. FetC was

405 found to be involved in iron homeostasis in Apergillus fumigates (64). FUR-dependent iron-

406 acquisition system was upregulated when Clostridium difficile tried to infect hamsters in iron-

407 depleted conditions (65).

408 Owing to the alkaline environment of the foregut, the E. mundtii living there highly express

409 alkaline shock proteins as protection against alkaline stress. Such was also the case in

410 Staphylococcus aureus (66). The alkaline shock protein helps the bacteria to adapt to extreme

411 stress conditions (67). All the F and V-type ATPases (atp, ntp genes), (Fig. 5b) show

412 downregulation in an alkaline environment. At high alkaline $\mathrm{pH}$, the proton motif force

413 decreases drastically, and lowers the activity of $\mathrm{H}^{+}$ATPases. These ATPases are related to

414 energy production and conversion. A similar trend was found in E. fecalis growing in an alkaline

415 environment (68). 
As facultative anaerobes, Enterococcus mundtii has the tendency to switch to fermentation inside

417 the host gut, although aerobic respiration is not completely stopped, since the genes for both are upregulated (fig 9). Oxygen may only be found in the near vicinity of the host gut surface, 50

$419 \mu \mathrm{m}$ distance onwards, for the facultative anaerobes, since there is none in the inner layers of the anaerobic gut wall (5). This tells us about the low oxygen levels in the gut lumen of most insects

421 (69). Pathway analysis clearly shows that conditions are favorable for starch and sucrose uptake through PTS transporters and metabolism. This is accounted for by the white-bean-based artificial diet that the host is fed on. The PTS transporters are immensely helpful for bacteria in general to survive environments with different levels of sugar (70). Nucleotide metabolism

425 shows enrichment owing to the fact that the bacteria are striving to colonize the gut of $S$.

426 littoralis. Previous studies with mice models showed that E. coli enriched their purine and 427 pyrimidine metabolism in order to colonize the mice intestines (26). Although E. mundtii likes to 428 save energy expenditure for its fatty acid and amino acid metabolism, their lysine metabolism is upregulated by bacteria living in the hindgut (9). Whether $S$. littoralis is obtaining lysine from their symbiotic E. mundtii, is a matter of further research. Pathway analysis shows enrichment

431 for lysine synthesis via the diaminopimelate pathway. Diaminopimelate also plays roles in 432 peptidoglycan synthesis (71).

434 insights into the strategies used by E. mundtii to survive the gut of $S$. littoralis, as real-time 435 information coming straight from the gut. The method optimized in this work can be put to 436 effective use for studying interactions between a pair of any host and its symbiont. For example, 437 the future prospects of this work include how 8-HQA is acting as a deciding factor in manipulating the bacterial community. A similar methodology will allow us to introduce 
439 fluorescently tagged bacteria into the insect guts that have been knocked out of the 8-HQA

440 producing gene, or any other gene that seems to be interesting for a symbiont's survival. Quite

441 similar to our method, the behavior of the retrieved bacteria studied with omics can tell us how

442 they act in such varying conditions. This way, we can delve deeper into interaction studies to

443 allow us a better understanding of mechanisms of survival and exchange occurring among

444 communicating partners in the environment.

445

446 
bioRxiv preprint doi: https://doi.org/10.1101/2020.02.03.932053; this version posted February 4, 2020. The copyright holder for this preprint (which was not certified by peer review) is the author/funder. All rights reserved. No reuse allowed without permission.

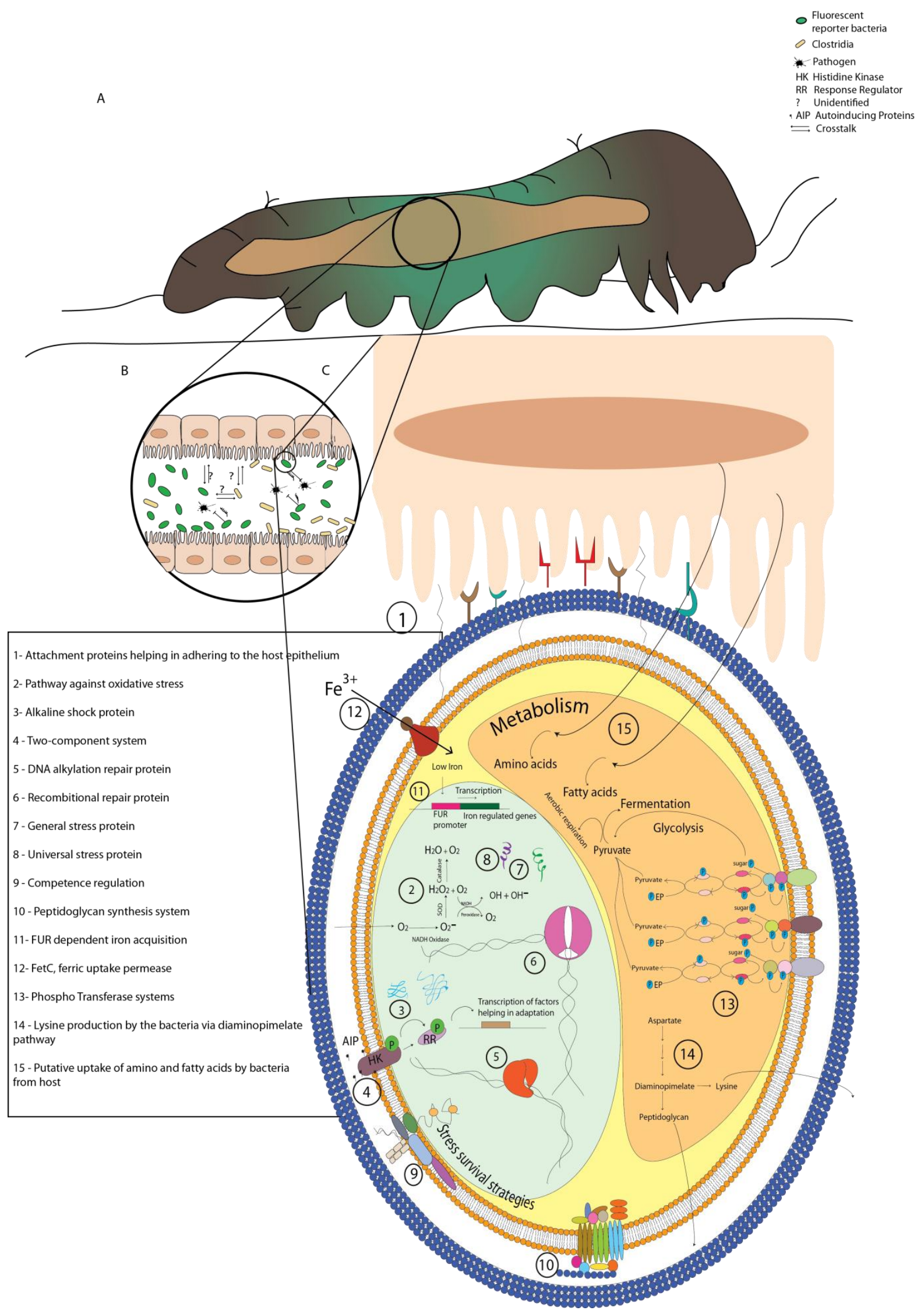


Figure 9: A snapshot of interactions between $S$. littoralis and its resident gut symbiont, $E$. mundtii. (A) An illustration of Spodoptera littoralis with its longitudinal gut (B) E. mundtii dominates in the gut along with Clostridia and keeps pathogens at bay by producing mundticiin KS. Unknown interactions occur among these two symbionts and the host gut. (C) Pathways and stress survival strategies of E. mundtii in the gut of $S$. littoralis.

\section{Materials and methods}

\section{Maintenance of eggs and larvae}

The eggs of Spodoptera littoralis were obtained from Syngenta Crop Protection Munchwielen AG (Munchwielen, Switzerland). Eggs were hatched at $14^{\circ} \mathrm{C}$ and the larvae were maintained at $24^{\circ} \mathrm{C}$ in an alternate 16 hours light period and 8 hours dark period. Larvae were reared on an agar-based artificial diet containing white beans, as described by Maffei et al (72).

\section{Bacterial strain}

A fluorescent strain of $E$. mundtii KD251 (isolated from the gut of $S$. littoralis in the Department of Bioorganic Chemistry) was constructed by transforming a GFP containing expression vector pTRKH3-ermGFP as described (18). This strain was grown in Todd-Hewitt Bouillon, THB (Roth, Karlsruhe, Germany) medium for both broth and 1.5\% agar (Roth, Karlsruhe, Germany), and in the presence of $5 \mu \mathrm{g} \mathrm{ml}^{-1}$ of erythromycin (Acros Organics, New Jersey, USA). The strain was preserved as a glycerol stock at $-80^{\circ} \mathrm{C}$.

\section{Introduction of the reporter bacteria into the insect microbiome}

A stationary phase culture of fluorescent reporter $E$. mundtii in THB broth containing $5 \mu \mathrm{g} \mathrm{m}{ }^{-1}$ of erythromycin was grown till mid-log phase with $\mathrm{OD}_{600} \sim 0.5-0.6$ at $37^{\circ} \mathrm{C}$ with shaking at 220 
$471 \mathrm{rpm}$. The culture was pelleted at $5000 \mathrm{x}$ g for 10 minutes at $4^{\circ} \mathrm{C}$ and resuspended in distilled

472 water. First-instar $S$. littoralis larvae $(n=120)$ were fed small cubes of artificial diet

473 supplemented with two antibiotics, ampicillin $\left(5.75 \mu \mathrm{gml}^{-1}\right)($ EMD Millipore corp., Billerica,

$474 \mathrm{MA}, \mathrm{USA})$ and erythromycin $\left(9.6 \mu \mathrm{gml}^{-1}\right)$ for 3 days, to reduce the already existing bacterial

475 load, before being fed with (at second instar) $100 \mu$ from the $1: 10$ dilution broth $\left(\sim 10^{\wedge} 10\right.$ cells)

476 containing fluorescent E. mundtii as described (18). These larvae were allowed to grow until fifth

477 instar, until sample preparation for FACS.

478 Sample preparation for FACS

479 A total of 30 fifth-instar larvae for each gut region, foregut and hindgut were dissected with

480 sterile forceps and scissors in a sterile clean bench. Following dissection, the gut tissues were

481 immediately submerged in $10 \mathrm{ml}$ of RNAlater solution (Invitrogen, Vilnius, Lithuania). Tissues

482 submerged in RNAlater solution were mixed with $2 \mathrm{ml}$ of $6 \%$ (w/v) betaine (Sigma Aldrich, St.

483 Louis, MO, USA) and placed on ice prior to crushing with mortar and pestle until gut

484 homogenates were formed. Thereafter, fluorescent E. mundtii were separated from the intestinal

485 debris by filtration through $40 \mu \mathrm{m}$ pore-size cell strainers (Falcon, NY, USA). The filtrates were

486 then separated into aliquots of $600 \mu \mathrm{l}$ each and kept at $-80^{\circ} \mathrm{C}$ for the sorting experiment.

\section{Cell sorting by FACS}

488 The gut homogenates were analyzed using BD FACSAria ${ }^{\mathrm{TM}}$ Fusion Cell Sorter (Becton

489 Dickinson, Heidelberg, Germany). It utilizes an ion laser emitting a $488 \mathrm{~nm}$ wavelength, and a

490502 long pass filter, followed by a 530/30 band pass filter. The green fluorescent protein emits

491 light with a peak wavelength of $530 \mathrm{~nm}$. The cells were sorted at a flow rate ranging between 10

$492 \mu \operatorname{lmin}^{-1}-80 \mu \operatorname{lmin}^{-1}$. The sorting was done in a single-cell mode and the sorted cells were 
collected in $5 \mathrm{ml}$ sterile Polypropylene round-bottom tubes (Falcon, Mexico). The cells were collected for a period of 3 hours which corresponded to an acquisition of 6000-7000 events/sec. The flow cytometry grade of PBS buffer (Thermo Fischer, Wilmington, USA) at pH of 7.4 was used as the sheath fluid. A total of $\sim 250,000$ cells were sorted from each sample, into $1 \mathrm{ml}$ of RNA Protect solution (Qiagen, Hilden, Germany)

\section{RNA extraction and sequencing}

As controls, E. mundtii broth cultures $(10 \mathrm{ml}, n=3)$ were grown to exponential growth $\left(\mathrm{OD}_{600}\right.$ $\sim 0.5-0.6)$ and centrifuged at $5000 \mathrm{x}$ g for $15 \mathrm{~min}$ at $4^{\circ} \mathrm{C}$ to pellet the bacterial cells. Bacterial cells were washed once with sterile phosphate-buffered saline (PBS) and resuspended with the same buffer at a concentration of approximately $10^{10} \mathrm{CFU} \mathrm{ml}{ }^{-1}$. The FACS-sorted fluorescent bacterial cells $(\sim 250,000)$ each from foregut and hindgut were pelleted by centrifugation at $5000 \mathrm{xg}$ for $10 \mathrm{~min}$ at $4^{\circ} \mathrm{C}$, leaving insect cell debris in the supernatant. The foregut, hindgut and E. mundtii cultures were each represented by three biological replicates $(n=3)$. RNAlater was removed from the sorted cells prior to RNA isolation and total RNA was isolated from the pelleted cells using the RNeasy mini kit (Qiagen, Hilden, Germany) following the manufacturer's instructions with some modifications. Pelleted bacterial cells were lysed enzymatically for 15 min at $37^{\circ} \mathrm{C}$ (enzymatic mix: $1 \mathrm{X}$ TE buffer, $\mathrm{pH} 8$ (Applichem $\mathrm{GmbH}$, Darmstadt, Germany), pH 8.0, $5 \mu \mathrm{g} \mathrm{ml}^{-1}$ lysozyme (Sigma Aldrich, St. Louis, MO,USA) and 50 $\mathrm{Uml}^{-1}$ mutanolysin (Sigma Aldrich, St. Louis, MO,USA)). All samples were DNase-treated with on-column DNase digestion per the manufacturer's protocol prior to RNA isolation. The concentration of total RNA of controls was diluted to match the bacterial concentration at single cell level. RNA was further cleaned and concentrated using Concentrator kit (Zymo Research, USA) yielding about $12 \mu \mathrm{l}$ in final volume ( 10 ng). The purified RNA was linearly amplified 
using MessageAmp II bacterial RNA amplification kit (Invitrogen, Vilnius, Lithuania) using 10

517 ng of total RNA following the manufacturer's instructions. The amplified RNA (aRNA) was

518 concentrated by precipitation with $5 \mathrm{M}$ ammonium acetate.

519 The quality and quantity of the total RNA was measured with a NanoDrop One

520 Spectrophotometer (Thermo Scientific, Wilmington, USA) and an Agilent 2100 Bioanalyzer

521 (Agilent Technologies, Palo Alto, CA, USA). RNA samples were sent to the Max Planck

522 Genome Centre in Cologne for RNA sequencing. A total of $0.3 \mu \mathrm{g}-1 \mu \mathrm{g}$ of amplified RNA was

523 used for cDNA library preparation using the Ultra-Low Input RNA kit following the Illumina

524 protocol at the Max Planck Genome Centre, Cologne. Sequencing was carried out on the HiSeq

5252500 sequencer at Cologne and a total of approximately 10 million paired-end reads $(2 \times 150$

526 bp) were generated for each sample.

$528 \quad$ RNA-seq data analysis

529 FastQC was done for an initial quality analysis of the reads. Analysis of the reads, including

530 trimming of adapters and differential gene expression analysis was done on LINUX-based

531 Command line interface, following the Tuxedo protocol (73). The adapters were trimmed using

532 Trimmomatic 0.36 , trimmed reads were assembled using Tophat 2.1.0, and mapped to the

533 genome of Enterococcus mundtii QU25 (23) using Cufflinks 2.2.0. The read counts were

534 normalized with FPKM (Fragments of Kilobase of transcripts per Million mapped reads)

535 (supplementary S6) and assemblies were merged using Cuffmerge. Cuffdiff was used to

536 compute the differentially expressed genes between $E$. mundtii from the larval gut and E. mundtii

537 grown in vitro. Based on homology to protein families, the proteins that were predicted for $E$. 
mundtii were categorized under Gene Ontology terms (http://geneontology.org). The genes were also mapped to the KEGG database to predict the pathways (supplementary). The results of differentially expressed genes were visualized using R-package CummeRbund 2.0, on R version 3.3.3 (2017-03-06). This R-package generated all the plots: dendrograms, volcano plots and histograms. The PCA plot was made using Statistics Toolbox of Matlab 2007a. A fold-change of $\geq 2$ was has been used as a threshold to analyze the differentially expressed genes.

\section{Acknowledgements}

This work was funded by the Max Planck Society and Jena School for Microbial

Communications. Also, we thank Angelika Berg and Andrea Lehr for technical assistance and Emily Wheeler for editorial assistance.

\section{References}

1. Engel $P$, Moran NA. The gut microbiota of insects-diversity in structure and function. FEMS microbiology reviews. 2013;37(5):699-735.

2. Dillon RJ, Dillon VM. The gut bacteria of insects: nonpathogenic interactions. Annual review of entomology. 2004;49:71-92.

\section{Shao Y, Chen B, Sun C, Ishida K, Hertweck C, Boland W. Symbiont-Derived Antimicrobials} Contribute to the Control of the Lepidopteran Gut Microbiota. Cell chemical biology. 2017;24(1):66-75. 4. Lee JB, Byeon JH, Jang HA, Kim JK, Yoo JW, Kikuchi Y, et al. Bacterial cell motility of Burkholderia gut symbiont is required to colonize the insect gut. Febs Lett. 2015;589(19):2784-90.

5. Tang X, Freitak D, Vogel H, Ping L, Shao Y, Cordero EA, et al. Complexity and variability of gut commensal microbiota in polyphagous lepidopteran larvae. PloS one. 2012;7(7):e36978.

6. Russell JA, Moran NA. Horizontal transfer of bacterial symbionts: heritability and fitness effects in a novel aphid host. Appl Environ Microb. 2005;71(12):7987-94.

7. Kirsch R, Gramzow L, Theißen G, Siegfried BD, Heckel DG, Pauchet Y. Horizontal gene transfer and functional diversification of plant cell wall degrading polygalacturonases: key events in the evolution of herbivory in beetles. Insect biochemistry and molecular biology. 2014;52:33-50.

8. Van Arnam EB, Currie CR, Clardy J. Defense contracts: molecular protection in insect-microbe symbioses. Chemical Society reviews. 2018;47(5):1638-51. 
9. Russell CW, Poliakov A, Haribal M, Jander G, van Wijk KJ, Douglas AE. Matching the supply of bacterial nutrients to the nutritional demand of the animal host. Proceedings of the Royal Society B: Biological Sciences. 2014;281(1791):20141163.

10. Salem H, Bauer E, Kirsch R, Berasategui A, Cripps M, Weiss B, et al. Drastic genome reduction in an herbivore's pectinolytic symbiont. Cell. 2017;171(7):1520-31. e13.

11. Brune A. Symbiotic digestion of lignocellulose in termite guts. Nature reviews Microbiology. 2014;12(3):168-80.

12. Schafer A, Konrad R, Kuhnigk T, Kampfer $\mathrm{P}$, Hertel $\mathrm{H}$, Konig $\mathrm{H}$. Hemicellulose-degrading bacteria and yeasts from the termite gut. The Journal of applied bacteriology. 1996;80(5):471-8.

13. Poliakov A, Russell CW, Ponnala L, Hoops HJ, Sun Q, Douglas AE, et al. Large-scale label-free quantitative proteomics of the pea aphid-Buchnera symbiosis. Molecular \& Cellular Proteomics. 2011;10(6):M110. 007039.

14. Florez LV, Scherlach K, Gaube P, Ross C, Sitte E, Hermes C, et al. Antibiotic-producing symbionts dynamically transition between plant pathogenicity and insect-defensive mutualism. Nat Commun. 2017;8.

15. Hammer TJ, Janzen DH, Hallwachs W, Jaffe SP, Fierer N. Caterpillars lack a resident gut microbiome. Proceedings of the National Academy of Sciences of the United States of America. 2017;114(36):9641-6.

16. Wieczorek H, Beyenbach KW, Huss M, Vitavska O. Vacuolar-type proton pumps in insect epithelia. Journal of Experimental Biology. 2009;212(11):1611-9.

17. Funke M, Buchler R, Mahobia V, Schneeberg A, Ramm M, Boland W. Rapid hydrolysis of quorum-sensing molecules in the gut of lepidopteran larvae. Chembiochem : a European journal of chemical biology. 2008;9(12):1953-9.

18. Teh B-S, Apel J, Shao Y, Boland W. Colonization of the intestinal tract of the polyphagous pest Spodoptera littoralis with the GFP-tagged indigenous gut bacterium Enterococcus mundtii. Frontiers in microbiology. 2016;7:928.

19. Hanchi H, Mottawea W, Sebei K, Hammami R. The Genus Enterococcus: Between Probiotic Potential and Safety Concerns-An Update. Frontiers in microbiology. 2018;9.

20. Magni C, Espeche C, Repizo GD, Saavedra L, Suarez CA, Blancato VS, et al. Draft genome sequence of Enterococcus mundtii CRL1656. Journal of bacteriology. 2012;194(2):550.

21. Pesek J, Svoboda J, Sattler M, Bartram S, Boland W. Biosynthesis of 8-hydroxyquinoline-2carboxylic acid, an iron chelator from the gut of the lepidopteran Spodoptera littoralis. Organic \& biomolecular chemistry. 2015;13(1):178-84.

22. Skaar EP. The Battle for Iron between Bacterial Pathogens and Their Vertebrate Hosts. Plos Pathog. 2010;6(8).

23. Shiwa $\mathrm{Y}$, Yanase $\mathrm{H}$, Hirose $\mathrm{Y}$, Satomi S, Araya-Kojima $\mathrm{T}$, Watanabe $\mathrm{S}$, et al. Complete genome sequence of Enterococcus mundtii QU 25, an efficient L-(+)-lactic acid-producing bacterium. DNA research. 2014;21(4):369-77.

24. Scheurwater EM, Pfeffer JM, Clarke AJ. Production and purification of the bacterial autolysin Nacetylmuramoyl-L-alanine amidase B from Pseudomonas aeruginosa. Protein expression and purification. 2007;56(1):128-37.

25. Kodrík $D$, Bednářová $A$, Zemanová $M$, Krishnan N. Hormonal regulation of response to oxidative stress in insects - an update. International journal of molecular sciences. 2015;16(10):25788-816.

26. Vogel-Scheel J, Alpert C, Engst W, Loh G, Blaut M. Requirement of purine and pyrimidine synthesis for colonization of the mouse intestine by Escherichia coli. Appl Environ Microbiol. 2010;76(15):5181-7. 
27. Prem Anand AA, Vennison SJ, Sankar SG, Gilwax Prabhu DI, Vasan PT, Raghuraman T, et al. Isolation and characterization of bacteria from the gut of Bombyx mori that degrade cellulose, xylan, pectin and starch and their impact on digestion. Journal of Insect Science. 2010;10(1):107.

28. Otto M. Physical stress and bacterial colonization. FEMS microbiology reviews. 2014;38(6):1250-

70.

29. Voronina OL, Kunda MS, Ryzhova NN, Aksenova El, Semenov AN, Romanova YM, et al. Burkholderia contaminans Biofilm Regulating Operon and Its Distribution in Bacterial Genomes. BioMed research international. 2016;2016.

30. Li YH, Tian X. Quorum sensing and bacterial social interactions in biofilms. Sensors. 2012;12(3):2519-38.

31. Tellam RL, Wijffels G, Willadsen P. Peritrophic matrix proteins. Insect biochemistry and molecular biology. 1999;29(2):87-101.

32. Sanchez B, Gonzalez-Tejedo C, Ruas-Madiedo P, Urdaci MC, Margolles A. Lactobacillus plantarum Extracellular Chitin-Binding Protein and Its Role in the Interaction between Chitin, Caco-2 Cells, and Mucin. Appl Environ Microb. 2011;77(3):1123-6.

33. Hancock LE, Murray BE, Sillanpaa J. Enterococcal Cell Wall Components and Structures. In: Gilmore MS, Clewell DB, Ike Y, Shankar N, editors. Enterococci: From Commensals to Leading Causes of Drug Resistant Infection. Boston2014.

34. Kovacs-Simon A, Titball RW, Michell SL. Lipoproteins of bacterial pathogens. Infection and immunity. 2011;79(2):548-61.

35. Antunes LC, Ferreira RB, Buckner MM, Finlay BB. Quorum sensing in bacterial virulence. Microbiology. 2010;156(Pt 8):2271-82.

36. Kim H, Goo E, Kang Y, Kim J, Hwang I. Regulation of universal stress protein genes by quorum sensing and RpoS in Burkholderia glumae. Journal of bacteriology. 2012;194(5):982-92.

37. Rao CVS, De Waelheyns E, Economou A, Anne J. Antibiotic targeting of the bacterial secretory pathway. Biochimica et biophysica acta. 2014;1843(8):1762-83.

38. Nicholson SA, Smalley D, Smith CJ, Abratt VR. The recA operon: A novel stress response gene cluster in Bacteroides fragilis. Research in microbiology. 2014;165(4):290-9.

39. Webb BL, Cox MM, Inman RB. Recombinational DNA repair: the RecF and RecR proteins limit the extension of RecA filaments beyond single-strand DNA gaps. Cell. 1997;91(3):347-56.

40. Ishag HZA, Xiong $Q$, Liu M, Feng Z, Shao G. E. coli recA gene improves gene targeted homologous recombination in Mycoplasma hyorhinis. Journal of microbiological methods. 2017;136:49-56.

41. Rubinson EH, Metz AH, O'Quin J, Eichman BF. A new protein architecture for processing alkylation damaged DNA: the crystal structure of DNA glycosylase AlkD. Journal of molecular biology. 2008;381(1):13-23.

42. Ivanov EL, Haber JE. DNA repair: RAD alert. Current Biology. 1997;7(8):R492-R5.

43. Kolodkin-Gal I, Verdiger R, Shlosberg-Fedida A, Engelberg-Kulka H. A differential effect of E. coli toxin-antitoxin systems on cell death in liquid media and biofilm formation. PloS one. 2009;4(8):e6785. 44. Schrettl M, Haas H. Iron homeostasis--Achilles' heel of Aspergillus fumigatus? Current opinion in microbiology. 2011;14(4):400-5.

45. van Vliet AH, Stoof J, Vlasblom R, Wainwright SA, Hughes NJ, Kelly DJ, et al. The role of the Ferric Uptake Regulator (Fur) in regulation of Helicobacter pylori iron uptake. Helicobacter. 2002;7(4):237-44. 46. Ageno M, Dore E, Frontali C. The alkaline denaturation of DNA. Biophysical Journal. 1969;9(11):1281.

47. Müller M, Reiß S, Schlüter R, Mäder U, Beyer A, Reiß W, et al. Deletion of membrane-associated Asp 23 leads to upregulation of cell wall stress genes in S taphylococcus aureus. Molecular microbiology. 2014;93(6):1259-68. 
48. Ran S, Liu B, Jiang W, Sun Z, Liang J. Transcriptome analysis of Enterococcus faecalis in response to alkaline stress. Frontiers in microbiology. 2015;6:795.

49. Sengupta R, Altermann E, Anderson RC, McNabb WC, Moughan PJ, Roy NC. The role of cell surface architecture of lactobacilli in host-microbe interactions in the gastrointestinal tract. Mediators of inflammation. 2013;2013.

50. Marraffini LA, DeDent AC, Schneewind O. Sortases and the art of anchoring proteins to the envelopes of gram-positive bacteria. Microbiology and Molecular Biology Reviews. 2006;70(1):192-221. 51. Navarre WW, Schneewind O. Proteolytic cleavage and cell wall anchoring at the LPXTG motif of surface proteins in Gram-positive bacteria. Molecular microbiology. 1994;14(1):115-21.

52. Boekhorst J, Wels M, Kleerebezem M, Siezen RJ. The predicted secretome of Lactobacillus plantarum WCFS1 sheds light on interactions with its environment. Microbiology. 2006;152(11):317583.

53. Hidalgo IJ, Raub TJ, Borchardt RT. Characterization of the human colon carcinoma cell line (Caco2) as a model system for intestinal epithelial permeability. Gastroenterology. 1989;96(3):736-49.

54. Brinster S, Furlan S, Serror P. C-terminal WxL domain mediates cell wall binding in Enterococcus faecalis and other gram-positive bacteria. Journal of bacteriology. 2007;189(4):1244-53.

55. Campbell PM, Cao AT, Hines ER, East PD, Gordon KH. Proteomic analysis of the peritrophic matrix from the gut of the caterpillar, Helicoverpa armigera. Insect biochemistry and molecular biology. 2008;38(10):950-8.

56. Wijffels G, Eisemann C, Riding G, Pearson R, Jones A, Willadsen P, et al. A novel family of chitin binding proteins from insect type 2 peritrophic matrix: CDNA sequences, chitin binding activity and cellular localisation. Journal of Biological Chemistry. 2001.

57. Tran HT, Barnich N, Mizoguchi E. Potential role of chitinases and chitin-binding proteins in hostmicrobial interactions during the development of intestinal inflammation. Histology and histopathology. 2011;26(11):1453.

58. Turrens JF. Mitochondrial formation of reactive oxygen species. The Journal of physiology. 2003;552(Pt 2):335-44.

59. Paes MC, Oliveira MB, Oliveira PL. Hydrogen peroxide detoxification in the midgut of the bloodsucking insect, Rhodnius prolixus. Archives of insect biochemistry and physiology. 2001;48(2):63-71. 60. Tomusiak-Plebanek A, Heczko P, Skowron B, Baranowska A, Okoń K, Thor PJ, et al. Lactobacilli with superoxide dismutase-like or catalase activity are more effective in alleviating inflammation in an inflammatory bowel disease mouse model. Drug design, development and therapy. 2018;12:3221. 61. Kim H, Goo E, Kang Y, Kim J, Hwang I. Regulation of universal stress protein genes by quorum sensing and RpoS in Burkholderia glumae. Journal of bacteriology. 2012;194(5):982-92. 62. Nyström T, Neidhardt FC. Cloning, mapping and nucleotide sequencing of a gene encoding a universal stress protein in Eschericha coli. Molecular microbiology. 1992;6(21):3187-98.

63. Cvitkovitch DG, Li Y-H, Ellen RP. Quorum sensing and biofilm formation in Streptococcal infections. The Journal of clinical investigation. 2003;112(11):1626-32.

64. Haas H. Iron-a key nexus in the virulence of Aspergillus fumigatus. Frontiers in microbiology. 2012;3:28.

65. Ho TD, Ellermeier CD. Ferric Uptake Regulator Fur control of Putative Iron Acquisition Systems in Clostridium difficile. Journal of bacteriology. 2015:JB. 00098-15.

66. Kuroda $\mathrm{M}$, Ohta $\mathrm{T}$, Hayashi $\mathrm{H}$. Isolation and the gene cloning of an alkaline shock protein in methicillin-resistant Staphylococcus aureus. Biochemical and biophysical research communications. 1995;207(3):978-84.

67. Balaji S, Krishnan MV. In Silico analysis of Alkaline Shock proteins in Enterobacteria. Journal of Proteomics \& Bioinformatics. 2008;2:21-37. 
68. Wei J, Jingping L. Transcriptome analysis of Enterococcus faecalis in response to alkaline stress. Frontiers in microbiology. 2015;6:795. 69. Johnson KS, Barbehenn RV. Oxygen levels in the gut lumens of herbivorous insects. Journal of

711 Insect Physiology. 2000;46(6):897-903.

712 70. Kotrba P, Inui M, Yukawa H. Bacterial phosphotransferase system (PTS) in carbohydrate uptake and control of carbon metabolism. Journal of Bioscience and Bioengineering. 2001;92(6):502-17.

714 71. Pavelka M, Jacobs WR. Biosynthesis of diaminopimelate, the precursor of lysine and a 715 component of peptidoglycan, is an essential function of Mycobacterium smegmatis. Journal of 716 bacteriology. 1996;178(22):6496-507.

717 72. Maffei M, Bossi S, Spiteller D, Mithofer A, Boland W. Effects of feeding Spodoptera littoralis on 718 lima bean leaves. I. Membrane potentials, intracellular calcium variations, oral secretions, and 719 regurgitate components. Plant physiology. 2004;134(4):1752-62.

720 73. Trapnell C, Roberts A, Goff L, Pertea G, Kim D, Kelley DR, et al. Differential gene and transcript 721 expression analysis of RNA-seq experiments with TopHat and Cufflinks. Nature protocols. 2012;7(3):56272278. 